\title{
Impact of prematurity and the CTG repeat length on outcomes in congenital myotonic dystrophy
}

Yu Saito ${ }^{1}$ Kenta Matsumura ${ }^{2}$, Misao Kageyama ${ }^{3}$, Yuichi Kato ${ }^{4}$ Eiji Ohta ${ }^{5}$ Kiyoaki Sumi ${ }^{6}$ Takeshi Futatani and Taketoshi Yoshida ${ }^{1 *}$

\begin{abstract}
Objective: Patients with congenital myotonic dystrophy (CDM) tend to be born preterm. Although the CDM severity generally depends on the CTG repeat length, prematurity may also affect the prognosis in patients with CDM. Given that preterm birth is expected to increase the risk of CDM in newborns, we investigated the outcomes of newborns with CDM according to gestational age to assess prematurity and the CTG repeat length for predicting prognosis.

Results: We assessed the outcomes of 54 infants with CDM using data collected from our hospitals and previously published studies. The patients were divided into mild and severe groups based on clinical outcomes. Logistic regression analysis was performed to estimate odds ratios (ORs) for CDM prognosis according to gestational age and the CTG repeat length and to construct a predictive model. Logistic regression analysis showed both the CTG repeat and gestational age were significantly associated with severe outcomes in patients with CDM (OR: $32.27,95 \% \mathrm{Cl} 3.45-$ 300.7; $p=0.002$ and OR: $0.73,95 \% \mathrm{Cl} 0.58-0.93 ; p=0.0094$, respectively). This predictive model for CDM prognosis exhibited good sensitivity (63\%) and specificity (86\%). Both prematurity and the CTG repeat length were significantly associated with the CDM severity.
\end{abstract}

Keywords: Myotonic dystrophy, CTG repeat, Discrimination analysis, Prematurity, Predicting prognosis

\section{Introduction}

Myotonic dystrophy type 1 (DM1, OMIM \#160900) is an autosomal dominant disorder that affects skeletal and smooth muscles as well as the respiratory, gastrointestinal systems. DM1 is caused by an expansion of cytosinethymine-guanine (CTG) trinucleotide repeats in the $3^{\prime}$ untranslated region of the dystrophia myotonica protein kinase $(D M P K)$ gene [1-4]. DM1 demonstrates anticipation because the CTG repeat expansion in DMPK seems to increase with parental transmission, especially by mother [5]. The current clinical classification of DM1

\footnotetext{
*Correspondence: ytake@med.u-toyama.ac.jp

${ }^{1}$ Division of Neonatology, Maternal and Perinatal Center, Toyama

University Hospital, Toyama, Japan

Full list of author information is available at the end of the article
}

is based on age at onset and length of the CTG expansion; therefore, DM1 severity depends on the length of the CTG expansion [6-10]. Congenital DM (CDM) is the most severe form of DM1, and neonatal mortality ranges between $16 \%$ and $41 \%$ [11]. Although the disease severity generally dependent on CTG repeats size, there are wide spectrum of involvements in CDM patients $[12,13]$. The cause of death is mainly respiratory distress which may be correlated with the CTG repeat length $[6,8]$. The presence of respiratory distress can distinguish between mild and severe CDM [8]; therefore, the respiratory system is a vital organ for predicting prognosis in CDM newborns.

Most CDM newborns inherit DM1 from their mothers. Pregnant women with DM1 have a preterm delivery rate of approximately $30 \%-50 \%[8,14,15]$. Preterm newborns (gestational age less than 37 weeks) and low birth weight 
infants (less than $2500 \mathrm{~g}$ ) are generally accompanied by some complications caused by prematurity such as bronchopulmonary dysplasia (BPD) and intestinal movement disorder. Consequently, preterm CDM newborns transmitted especially by mother are assumed to be at a much higher risk for dysfunction of the pulmonary and intestinal systems because they are affected by the double risk factors of CDM and preterm birth. Since we expected preterm birth to increase the burden on CDM newborns, we investigated the outcomes of CDM newborns according to gestational age (prematurity) and the CTG repeat length for predicting prognosis.

\section{Main text \\ Methods \\ Data collection}

This retrospective case series collected patients information of newborns diagnosed with CDM in our six NICUs, which are all tertiary hospitals, from January 2002 to July 2019 in Japan. We obtained clinical data including gestational age, birth weight, length of hospital stay, outcome, and the CTG repeat length from the medical charts. In addition, CDM infants from previous literature published between January 2002 and July 2019 were included when at least gestational age, length of hospital stay, outcome, and the CTG repeat length had been reported. This study was reviewed and approved by the Toyama University Review Board (R2019038).

\section{Outcome analysis by combining the CTG repeat length and gestational age}

Length of hospital stay was used as a marker of CDM severity. CDM patients were classified into the mild group (i.e., a hospital stay of less than 1 year) or the severe group (i.e., death or a long hospital stay of more than 1 year). The choice of long hospital stay as the threshold was completely arbitrary, but Japanese national surveillance showed only $4.7 \%$ of newborns of NICU stayed in hospitals more than 1 year [16]. This long-term hospitalization was intuitively meaningful for distinguishing the severity of CDM infants. In case of preterm infants, hospital stay was calculated from expected date of birth. For the analysis of CTG repeat length, we adopted the median value if there were between 1800 and 2200 CTG repeats (2000 repeats in this case) and then applying a logarithmic transformation $\left(\log _{2}\right)$ to normalize the distribution. To investigate the outcomes of CDM infants, a logistic regression analysis was conducted to estimate odds ratio (OR) and its $95 \%$ confidence interval (CI) for CDM severity according to $\log _{2}$ CTG repeat length and gestational age and to construct a predictive model. A $p$ value of less than 0.05 was considered statistically significant, using SAS version 9.4 (SAS Institute Inc., Cary, NC, USA).

\section{Results}

We analyzed data on $22 \mathrm{CDM}$ infants from our hospitals and 31 patients from previous studies [17-33]. We summarized the clinical characteristics of all 53 CDM infants in Table 1. The median gestational age at delivery was 34.6 weeks (range, 23.5 to 42.1 weeks), with a preterm delivery rate of $70.4 \%$ (38/54 cases). The median neonatal birth weight was $2085 \mathrm{~g}$ (range: 526 to $3600 \mathrm{~g}$ ), with a low birth weight rate of $68.5 \%$ (37/54 cases). The CTG repeat length varied from 600 to 3000 (median 1700). By outcome, the mild group included 37 infants, whereas the severe group included 9 dead infants and 7 infants who required a long hospitalization. The median length of hospital stay in the infants that survived was 80 days (0 to 673).

Logistic regression analysis showed that both $\log _{2}$ CTG repeat length and gestational age were significantly associated with severe outcome of CDM patients (OR 32.27, 95\% CI 3.45-300.7; $p=0.002$ and OR 0.73, 95\% CI $0.58-0.93 ; p=0.0094$, respectively). Discriminant line, on which the probability of an infant will be classified into each outcome is the same, derived using this analysis was following:

$$
\begin{aligned}
& \log _{2} \text { CTG repeat length }=0.0890 \\
& \times \text { Gestational age (weeks) }+8.15
\end{aligned}
$$

Taking exponential transform of both sides leads to

$$
\text { CTG repeat length }=2^{(0.0890 \times \text { Gestational age (weeks) }+8.15)}
$$

According to this discriminant curve, CDM patients were divided into two groups based on their predictive prognosis: favorable and unfavorable groups (Fig. 1). This equation provided $63 \%$ sensitivity, $86 \%$ specificity, and a $67 \%$ positive predictive value.

\section{Discussion}

The clinical course of CDM in patients assessed in this study varied from one mild case (our case 16) without NICU admission to life-threatening illnesses (Table 1). Throughout this study, we provided a useful predictive prognosis model of CDM patients by combining gestational age and the CTG repeat length (Fig. 1). We revealed that OR decreased by $27 \%$ with 1 week increase in gestational age, whereas OR increased by 31.27 with 1 unit increase in $\log _{2}$ CTG repeat length, in other words, OR increased by 31.27 whenever the number of CTG repeat length doubled. The current clinical classification of DM1 is based on age at onset and CTG length [7, $12,13,34,35]$. On the other hand, several reports have 
Table 1 Summaries of clinical characteristics of congenital myotonic dystrophy

\begin{tabular}{|c|c|c|c|c|c|}
\hline Case & GA at birth (wk) & Birth weight(g) & No. of CTG repeats & Outcome & $\begin{array}{l}\text { Hospital } \\
\text { stay (d) }\end{array}$ \\
\hline Our cases 1 & 34 & 2174 & 1900 & 1 & 134 \\
\hline 2 & 23.5 & 526 & 2600 & 2 & 65 \\
\hline 3 & 40 & 3232 & 1820 & 1 & 43 \\
\hline 4 & 36 & 3096 & 1700 & 1 & 90 \\
\hline 5 & 26 & 982 & 2400 & 2 & 326 \\
\hline 6 & 36.3 & 2031 & 2100 & 2 & 3 \\
\hline 7 & 33.6 & 2085 & 1200 & 1 & 141 \\
\hline 8 & 35.4 & 2597 & 2100 & 2 & 2 \\
\hline 9 & 34.2 & 2252 & 2200 & 2 & 409 \\
\hline 10 & 35.5 & 2370 & 1000 & 1 & 43 \\
\hline 11 & 37.4 & 2886 & 1250 & 1 & 86 \\
\hline 12 & 37.4 & 2434 & 1450 & 1 & 100 \\
\hline 13 & 37.6 & 2226 & 1800 & 1 & 71 \\
\hline 14 & 38.2 & 2344 & 1400 & 1 & 71 \\
\hline 15 & 30 & 1190 & 1000 & 1 & 96 \\
\hline 16 & 37 & 2600 & 900 & 1 & 0 \\
\hline 17 & 37 & 2676 & 600 & 1 & 2 \\
\hline 18 & 25 & 758 & 1100 & 1 & 236 \\
\hline 19 & 33.1 & 2018 & 2200 & 2 & 2 \\
\hline 20 & 33.3 & 1656 & 2200 & 1 & 129 \\
\hline 21 & 28.3 & 848 & 1500 & 2 & 285 \\
\hline 22 & 31.3 & 1640 & 2400 & 1 & 160 \\
\hline Yamaguchi [17] & 37.6 & 2838 & 1375 & 1 & 49 \\
\hline \multirow[t]{9}{*}{ Yee [18] } & 34.6 & 2058 & 2700 & 2 & 397 \\
\hline & 36.6 & 2985 & 1300 & 1 & 29 \\
\hline & 38 & 3600 & 1100 & 1 & 20 \\
\hline & 38.2 & 3140 & 1300 & 1 & 21 \\
\hline & 29.1 & 1380 & 1000 & 1 & 260 \\
\hline & 38.5 & 3450 & 700 & 1 & 24 \\
\hline & 31.5 & 1710 & 1700 & 1 & 91 \\
\hline & 37 & 2850 & 1270 & 1 & 5 \\
\hline & 31 & 1640 & 2000 & 2 & 45 \\
\hline \multirow[t]{3}{*}{ Tsuji [19] } & 30 & 1322 & 1600 & 2 & 365 \\
\hline & 35 & 2618 & 2200 & 2 & 635 \\
\hline & 35 & 1892 & 1300 & 1 & 180 \\
\hline Yamashita [20] & 37.6 & 2876 & 2600 & 1 & 120 \\
\hline Fuma [21] & 31.6 & 1411 & 2500 & 2 & 730 \\
\hline \multirow[t]{2}{*}{ Banno [22] } & 37 & 2786 & 1100 & 1 & 80 \\
\hline & 36 & 2434 & 1650 & 1 & 70 \\
\hline Kanazawa [23] & 25.1 & 678 & 2100 & 2 & 61 \\
\hline Minami [24] & 40 & 2935 & 1630 & 1 & 40 \\
\hline Takagi [25] & 35.4 & 2266 & 2100 & 1 & 166 \\
\hline \multirow[t]{2}{*}{ Sato [26] } & 42.1 & 3378 & 2100 & 1 & 123 \\
\hline & 26.2 & 896 & 1000 & 1 & 153 \\
\hline Miyagi [27] & 29 & 1200 & 1800 & 2 & 17 \\
\hline Utunomiya [28] & 34.6 & 1890 & 2900 & 1 & 136 \\
\hline Kondo [29] & 23.3 & 660 & 1950 & 2 & 425 \\
\hline \multirow[t]{2}{*}{ Yanagi [30] } & 36.2 & 2410 & 1500 & 1 & 172 \\
\hline & 34.4 & 1724 & 1000 & 1 & 145 \\
\hline
\end{tabular}


Table 1 (continued)

\begin{tabular}{llllll}
\hline Case & GA at birth (wk) & Birth weight(g) & No. of CTG repeats & $\begin{array}{c}\text { Outcome } \\
\text { Hospital } \\
\text { stay (d) }\end{array}$ \\
\hline & 33.3 & 2014 & 3000 & 1 & 203 \\
Enomoto [31] & 33.1 & 2190 & 2900 & 2 & 545 \\
Saito [32] & 28.6 & 850 & 1700 & 1 & 221 \\
Nakayama [33] & 28.5 & 946 & 1750 & 1 & 240 \\
\hline
\end{tabular}

Outcome 1, discharge within 1 year; 2 , death or discharge after 1 year

$\mathrm{GA}$, gestational age

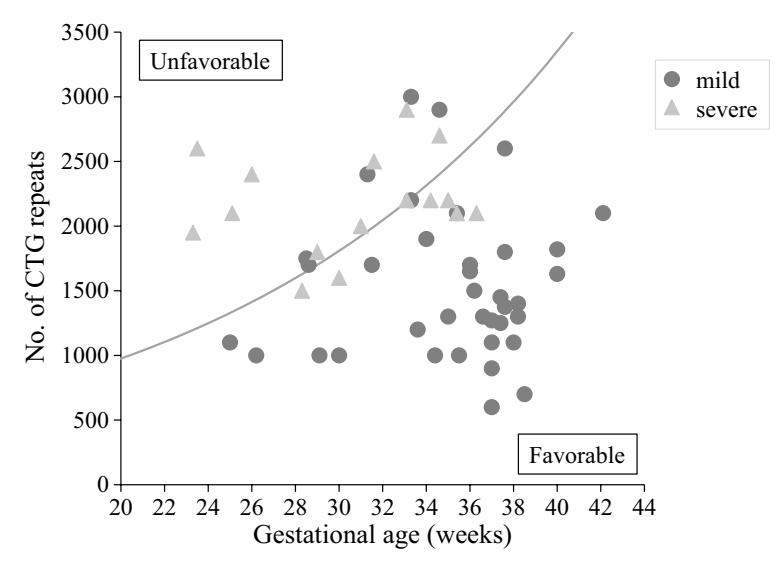

Fig. 1 Scatterplot of CDM patients according to the number of CTG repeats and gestational age. Discriminant curve distinguishing between favorable and unfavorable outcomes was derived using a multivariate logistic regression. See text for details

shown no evidence of an effect of CTG repeat length on clinical severity $[8,11,36]$. Since the severity of CDM depends on the status of respiratory complications [6], prematurity is supposed to worsen respiratory status. This discriminant curve increases according to gestational age in Fig. 1; therefore, prematurity is a concern for poor outcomes in CDM newborns. Our results suggest that it is crucial to take into account both prematurity and the CTG repeat length for predicting CDM prognosis.

Interestingly, all term newborns ( $>37$ weeks) with CDM showed a good prognosis. This may have occurred because these infants had enough time for their respiratory system to mature until term. CDM mortality rates range from $16 \%$ to $41 \%$ and are generally caused by respiratory insufficiency [11]. Preterm CDM newborns often require mechanical ventilation for a long period of time, which could worsen their lung function. It is important that CDM newborns remain in the uterus for as long as possible. Another reason for this finding is that the term CDM newborns had fewer CTG repeats (median: 1300) than preterm ones (median of 1900). Several studies have indicated the CTG repeat correlated with the disease phenotype $[8,34,35]$. Thus, having few CTG repeats with term CDM newborns induces a favorable outcome. Furthermore, information on GA at birth would be useful to predict the outcomes of preterm CDM newborns.

Approximately $30 \%-45 \%$ of pregnant women with DM1 undergo preterm labor and 17\%-25\% experience polyhydramnios $[14,15]$. In our study population, $68.2 \%$ of women had preterm labor (15/22 cases, Table 1) and $68.2 \%$ had polyhydramnios ( $15 / 22$ cases, data not shown). Case No. 3 (CTG repeats: 1820) with polyhydramnios had the amniotic fluid removed twice by amniocentesis at GA 28 weeks $(470 \mathrm{ml})$ and 34 weeks $(700 \mathrm{ml})$. Consequently, this patient was born at 40 weeks and displayed spontaneous breathing without mechanical ventilation. To prolong pregnancy in pregnant women with DM1, amniocentesis may help treat polyhydramnios. These data suggest the possibility of improvement in CDM infants. For example, when evaluating CTG repeat length from 1000 to 2000 repeats in Fig. 1, most patients who were less than GA 32 weeks had unfavorable outcomes. Conversely, patients more than GA 32 weeks all showed favorable outcomes (Fig. 1). These results highlight that the removal of amniotic fluid by amniocentesis may prolong the duration of pregnant mothers with DM1 and may improve outcomes in CDM infants.

\section{Conclusion}

This study showed that both gestational age and the CTG repeat length were associated with outcomes in CDM infants. We can predict the prognosis of CDM fetus or newborns based on gestational age and the CTG repeat length which may be helpful for medical staffs and their parents. Amniocentesis for polyhydramnios in mothers with DM1 may prolong the duration of pregnancy and improve outcomes in CDM infants.

\section{Limitations}

This study has several limitations. First is our data bias. This retrospective case series collected patients information of newborns diagnosed with CDM in our six NICUs, which are all tertiary hospitals in Japan. Our 
rate of preterm infants was much higher $(68.2 \%)$ than other reports $(30 \%-45 \%)[14,15]$, which indicates that our hospitals might treat more severe patients. Although we collected many data from literatures as a retrospective case study, there is no significant difference between our patients and literatures' patients regarding gestational age (mean $33.6 \mathrm{wk}$ vs $33.7 \mathrm{wk}$, $\mathrm{p}=0.98$ ), CTG repeat length (mean 1673.6 vs 1980.5 , $\mathrm{p}=0.32$ ), birth weight (mean $2028.2 \mathrm{~g}$ vs $2096.8 \mathrm{~g}$, $\mathrm{p}=0.76$ ), and hospital length (mean 113.4 days vs 189.6 days, $\mathrm{p}=0.09$ ). We believe to have reduced our data bias as little as possible. Second, our definition of severe includes death and a long stay in the hospital of more than 6 months. This length of hospital stay is completely arbitrary. However, this discriminant analysis showed such a high sensitivity and specificity that this time period could be useful for predicting prognosis. Further worldwide studies are necessary to more accurately predict the prognosis of CDM infants.

\section{Abbreviations}

CDM: Congenital Myotonic Dystrophy; CTG: Cytosine-Thymine-Guanine.

\section{Acknowledgements}

We would like to express our gratitude to all participants of this study, and all individuals involved in data collection.

\section{Author's contribution}

TY and YS designed the study. KM, MK, TY, YK, KS, EO and TF analyzed and interpreted the data. TY, YS and KM wrote the manuscript. All authors contributed to the critical revision of the manuscript. All authors read and approved the final manuscript.

\section{Funding}

The authors were supported by JSPS KAKENHI Grant Number 19 K08248.

\section{Availability of data and materials}

All data is confidential regarding patient information.

\section{Ethics approval and consent to participate}

This study was approved from the local ethics committee at Toyama University (R2019038). Written informed consent was obtained from all individual participants included in this study.

\section{Consent for publication}

Parental permission was obtained in writing for use of the de-identified case report.

\section{Competing interests}

The authors declare that they have no competing interests.

\begin{abstract}
Author details
${ }^{1}$ Division of Neonatology, Maternal and Perinatal Center, Toyama University Hospital, Toyama, Japan. ${ }^{2}$ Toyama Regional Center for Japan Environment and Children's Study, University of Toyama, Toyama, Japan. ${ }^{3}$ Department of Neonatology, OKAYAMA Medical Center, Okayama, Japan. ${ }^{4}$ Department of Neonatology, Anjo Kosei Hospital, Aichi, Japan. ${ }^{5}$ Department of Pediatrics, Fukuoka University, Fukuoka, Japan. ${ }^{6}$ Department of Pediatrics, Aizenbashi Hospital, Osaka, Japan. ${ }^{7}$ Department of Pediatrics, Toyama Prefectural Central Hospital, Toyama, Japan.
\end{abstract}

Received: 12 January 2020 Accepted: 15 July 2020

Published online: 23 July 2020

\section{References}

1. Brook JD, McCurrach ME, Harley HG, Buckler AJ, Church D, Aburatani H, et al. Molecular basis of myotonic dystrophy: expansion of a trinucleotide (CTG) repeat at the $3^{\prime}$ end of a transcript encoding a protein kinase family member. Cell. 1992;68:799-808.

2. Buxton J, Shelbourne P, Davies J, Jones C, Van Tongeren T, Aslanidis C, et al. Detection of an unstable fragment of DNA specific to individuals with myotonic dystrophy. Nature. 1992;355:547-8.

3. Fu YH, Pizzuti A, Fenwick RG Jr, King J, Rajnarayan S, Dunne PW, et al. An unstable triplet repeat in a gene related to myotonic muscular dystrophy. Science. 1992;255:1256-8.

4. Mahadevan M, Tsilfidis C, Sabourin L, Shutler G, Amemiya C, Jansen G, et al. Myotonic dystrophy mutation: an unstable CTG repeat in the $3^{\prime}$ untranslated region of the gene. Science. 1992;255:1253-5.

5. Dogan C, De Antonio M, Hamroun D, Varet H, Fabbro M, Rougier F, et al. Gender as a modifying factor influencing myotonic dystrophy type 1 phenotype severity and mortality: a nationwide multiple databases cross-sectional observational study. PLoS ONE. 2016;11:e0148264.

6. Monteiro R, Bento J, Gonçalves MR, Pinto T, Winck JC. Genetics correlates with lung function and nocturnal ventilation in myotonic dystrophy. Sleep Breath. 2013;17:1087-92.

7. Rudnik-Schöneborn S, Zerres K. Outcome in pregnancies complicated by myotonic dystrophy: a study of 31 patients and review of the literature. Eur J Obstet Gynecol Reprod Biol. 2004;114:44-53.

8. Echenne B, Rideau A, Roubertie A, Sébire G, Rivier F, Lemieux B. Myotonic dystrophy type I in childhood Long-term evolution in patients surviving the neonatal period. Eur J Paediatr Neurol. 2008:12:210-23.

9. Harper PS. Myotonic dystrophy. 3rd ed. London:W.B. Saunders; 2001.

10. Johnson NE, Aldana EZ, Angeard N, Ashizawa T, Berggren KN, Marini-Bettolo C, Duong T, Ekström AB, Sansone V, Tian C, Hellerstein L, Campbell C. Consensus-based care recommendations for congenital and childhoodonset myotonic dystrophy type 1. Neurol Clin Pract. 2019;9:443-54.

11. Campbell C, Levin S, Siu VM, Venance S, Jacob P. Congenital myotonic dystrophy: Canadian population-based surveillance study. J Pediatr. 2013:163:120-5.

12. Kroksmark AK, Ekström AB, Björck E, Tulinius M. Myotonic dystrophy: muscle involvement in relation to disease type and size of expanded CTG-repeat sequence. Dev Med Child Neurol. 2005;47:478-85.

13. Ekström AB, Hakenäs-Plate L, Samuelsson L, Tulinius M, Wentz E. Autism spectrum conditions in myotonic dystrophy type 1: a study on 57 individuals with congenital and childhood forms. Am J Med Genet B (Neuropsychiatr Genet.). 2008;147B:918-26.

14. Awater C, Zerres K, Rudnik-Schöneborn S. Pregnancy course and outcome in women with hereditary neuromuscular disorders: comparison of obstetric risks in 178 patients. Eur J Obstet Gynecol Reprod Biol. 2012;162:153-9.

15. Johnson NE, Hung M, Nasser E, Hagerman KA, Chen W, Ciafaloni E, et al. The impact of pregnancy on myotonic dystrophy: a registry-based study. J Neuromuscul Dis. 2015;2:447-52.

16. Yamagata Z. Actual situation of long-term hospitalization of low birth weight infants in Japan. J Japan Soc Neonatal Health Dev. 2001;13:141-7 (in japanese).

17. Yamaguchi K, Tanaka H, Furuhashi FH, Tanaka K, Kondo E, Ikeda T. Antenatal indomethacin treatment for congenital myotonic dystrophy. Case Rep Obstet Gynecol. 2019;2019:4290145.

18. Yee C, Choi SJ, Oh SY, Ki CS, Roh CR, Kim JH. Clinical characteristics of pregnancies complicated by congenital myotonic dystrophy. Obstet Gynecol Sci. 2017;60:323-8.

19. Tsuji T, Yokoi A, Yamada S, Wakisaka A, Nakamura N, Maruhashi K, et al. Three cases of congenital myotonic dystrophy with prolonged respiratory failure. No To Hattatsu (Tokyo). 2017;49(Suppl):S415 (in Japanese).

20. Yamashita T, Nozaki M, Obata K, Imanishi Y, I Iwaibara K, Motizuki N, et al. A case of systemic juvenile idiopathic arthritis with congenital myotonic dystrophy diagnosed at 8 months. J Japan Soc Neonatal Health Dev. 2016;28:655 (in Japanese).

21. Fuma K, Maseki Y, Ikeda S, Kuribayashi M, Okazaki A, Kihara K, et al. A rare case of myotonic dystrophy with rhabdomyolysis diagnosed during pregnancy due to oral ritodrine therapy for tocolysis. J Jpn Soc Perin Neon Med. 2016;52:1194-8 (in Japanese).

22. Banno H, Kawahara K, Sato K, Takahashi J, Nishijima K, Yoshida Y. A careful history-taking is critically important for diagnosis of myotonic dystrophy 
for pregnant women with hydramnion. Sanka To Fujinka (Tokyo). 2016;83:451-4.

23. Kanazawa M, Ogasawara K, Maeda S, Kanai Y, Gou Y, Imamura T, et al. A case of extremely preterm infant with congenital myotonic dystrophy born from myotonic dystrophy mother. J Jpn Soc Perin Neon Med. 2015;51:826 (in Japanese).

24. Minami S, Ota N, Shiro M, Yagi S, Mabuti Y, Kumagaya K, et al. A case of congenital myotonic dystrophy which was confused by the amniotic fluid test. Japanese J Genetic Counseling. 2015;36:104 (in Japanese).

25. Takagi K, Matsubara K, Yasuoka T, Inoue A, Kondo E, Uchikura Y, et al. A case of congenital myotonic dystrophy-induced hydramnion. Modern Trends Obst Gynecol. 2015;63:341-4 (in Japanese).

26. Sato T, Yamasaki H, Nagayama Y. Two cases of congenital myotonic dystrophy. J Jpn Soc Perin Neon Med. 2014;50:829 (in Japanese).

27. Miyagi N, Shimoti Y, Oniwa T, Oshiro T. A case of very low birth weight infant with congenital myotonic dystrophy born from undiagnosed myotonic dystrophy mother. J Jpn Soc Perin Neon Med. 2014;50:826 (in Japanese)

28. Utsunomiya G, Imai K, Yamakawa M. A case of congenital myotonic dystrophy with marked CTG repeats. J Jpn Soc Perin Neon Med. 2012:48:510 (in Japanese).

29. Kondo M, Morita K, Takano Y, Tuchida S, Kushima R, Omori I, et al. A case report of congenital myotonic dystrophy, born at 23 weeks of gestation. $J$ Jpn Soc Perin Neon Med. 2010;46:739 (in Japanese).

30. Yanagi Y, Koshida S. Three cases report of congenital myotonic dystrophy. J Jpn Soc Perin Neon Med. 2008;44:631 (in Japanese).
31. Enomoto M, Morioka I, Fujibayashi H, Awano H, Sato Y, Shibata A, et al. A survival case of severe congenital myotonic dystrophy with hydrops fetalis and chylothorax. J Japan Soc Neonatal Health Dev. 2008;20:85-90 (in Japanese).

32. Saito M, Miyazono Y, Yamada M. A case of extremely preterm infant with congenital myotonic dystrophy. J Jpn Soc Perin Neon Med. 2005;41:502 (in Japanese)

33. Nakayama Y, Imamura H. A case of extremely preterm infant with congenital myotonic dystrophy who indicated prolonged respiratory failure. J Jpn Soc Neonatal Health Dev. 2006;18:49-52 (in Japanese).

34. Tsilfidis C, MacKenzie AE, Mettler G, Barceló J, Korneluk RG. Correlation between CTG trinucleotide repeat length and frequency of severe congenital myotonic dystrophy. Nat Genet. 1992;1:192-5.

35. Kim HJ, Na JH, Lee YM. Genotype-phenotype correlations in pediatric patients with myotonic dystrophy type 1. Korean J Pediatr. 2019;62:55-61.

36. Verpoest W, Seneca S, De Rademaeker M, Sermon K, De Rycke M, De Vos $M$, et al. The reproductive outcome of female patients with myotonic dystrophy type 1 (DM1) undergoing PGD is not affected by the size of the expanded CTG repeat tract. J Assist Reprod Genet. 2010;27:327-33.

\section{Publisher's Note}

Springer Nature remains neutral with regard to jurisdictional claims in published maps and institutional affiliations.
Ready to submit your research? Choose BMC and benefit from:

- fast, convenient online submission

- thorough peer review by experienced researchers in your field

- rapid publication on acceptance

- support for research data, including large and complex data types

- gold Open Access which fosters wider collaboration and increased citations

- maximum visibility for your research: over $100 \mathrm{M}$ website views per year

At BMC, research is always in progress.

Learn more biomedcentral.com/submissions 